\title{
Prognostic significance of splenectomy during completion total gastrectomy in patients with remnant gastric cancer: propensity score matching analysis
}

\author{
Seung Hyun Back, Sung Eun Oh, Ji Yeong An, Min-Gew Choi, Tae Sung Sohn, Jae Moon Bae, Jun Ho Lee \\ Department of Surgery, Samsung Medical Center, Sungkyunkwan University School of Medicine, Seoul, Korea
}

\begin{abstract}
Purpose: Splenectomy for patients with remnant gastric cancer has been controversial. The purpose of this study is to identify the impact of splenectomy in the treatment of remnant gastric cancer.

Methods: We retrospectively analyzed 285 patients with remnant gastric cancer who underwent completion total gastrectomy with or without splenectomy in Samsung Medical Center, between September 1996 and December 2017. We used a 1:1 propensity score matching method for the analysis. The matching factors were age, sex, and pathologic stage. After the matching process, we compared the 5-year overall survival (OS) and the disease-free survival (DFS) between patients with and without splenectomy during completion total gastrectomy.

Results: The median duration of follow-up was 58.0 months (range, 0-132 months). After propensity score matching, there were no statistically significant differences between the splenectomy group $(n=77)$ and no splenectomy group $(n=77)$ in terms of clinicopathological features. The 5-year OS rate between the no splenectomy and splenectomy group were not significantly different. There was no significant difference between 5-year DFS of the matched groups. Multivariate analysis revealed that splenectomy is not a significant prognostic factor in terms of 5 -year OS (no splenectomy vs. splenectomy; $61.5 \%$ vs. $60.2 \%, \mathrm{P}=0.884$ ) or DFS (74.9\% vs. $69.8 \%, \mathrm{P}=0.880$ ).

Conclusion: Splenectomy has no impact on the OS and DFS in patients with remnant gastric cancer. Splenectomy during completion total gastrectomy may not be necessary.
\end{abstract}

Keywords: Splenectomy, Remnant gastric cancer, Completion total gastrectomy, Survival

\section{INTRODUCTION}

Stomach cancer is the fourth most common cancer in the world [1]. Among all stomach cancers, the relative rate of remnant gastric cancer is $1 \%$ to $8 \%$ [2]. The original definition of remnant gastric

Received: Sep 22, 2021 Accepted: Nov 5, 2021

Correspondence to: Jun Ho Lee

Department of Surgery, Samsung Medical Center, Sungkyunkwan

University School of Medicine, 81 Irwon-ro, Gangnam-gu, Seoul 06351, Korea

Tel: +82-2-3410-3463, Fax: +82-2-3410-6981

E-mail: gsjunholee@gmail.com

ORCID: Jun Ho Lee (https://orcid.org/0000-0002-0131-1527)

Copyright (c) 2021 Korean Society of Surgical Oncology

This is an Open Access article distributed under the terms of the Creative Commons Attribution Non-Commercial License (http://creativecommons.org/licenses/by-nc/4.0) which permits unrestricted non-commercial use, distribution, and reproduction in any medium, provided the original work is properly cited. cancer was stomach cancer that was discovered at least 5 years after distal gastrectomy for benign disease [3,4]. Recently it has been used to define any cancer that develops in the remnant stomach that remains after partial gastrectomy irrelevantly of the initial diagnosis or surgery [5].

Optimal surgical treatment for remnant gastric cancer has not been determined [6]. Although completion total gastrectomy is the only surgical treatment for remnant gastric cancer, secondary surgery is never straightforward for reasons such as anatomical alteration and adhesions in the abdominal cavity [7]. The frequent resection of other organs and dissection of lymph nodes also make surgery difficult [8].

According to previous studies, patients with metastases of splenic hilar lymph nodes in patients with gastric cancer have a poor prognosis even after therapeutic surgery [9]. In remnant gastric cancer, lymphatic flow and the incidence of lymph node metastasis 
are ambiguous [10]. Therefore, the lymph node metastasis pattern of remnant gastric cancer may be different from that of primary gastric cancer and surgery for this may require a modified lymph node dissection to include all important lymph node stations [11], including the lymph node station no. 10.

The effectiveness of splenectomy during the treatment of remnant gastric cancer is uncertain. Therefore, we conducted a retrospective study how splenectomy affects survival in patients who underwent complete total gastrectomy for remnant gastric cancer using propensity score matching analysis.

\section{METHODS}

We retrospectively reviewed the medical records of 390 patients diagnosed with remnant gastric cancer who had surgery in Samsung Medical Center, between September 1996 and December 2017. Remnant gastric cancer was defined as any cancer that develops in the remnant stomach that remains after partial gastrectomy irrelevantly of the initial diagnosis or surgery. Among them, we excluded the patients who were diagnosed with stage IV $(n=37)$, other solid tumors $(\mathrm{n}=9)$, and those who had non-curative resection $(n=11)$. The patients diagnosed with other histologic types of gastric cancer (neuroendocrine carcinoma G3, $\mathrm{n}=1$ ) was also excluded in the analysis. We set the minimum follow-up period to be 3 years so that surgery after December 2017 was excluded $(n=47)$. All included patients $(\mathrm{n}=285)$ had completion total gastrectomy with or without splenectomy. After surgery, the patients were followed through scheduled outpatient visits. During their follow-up period, esophagogastroduodenoscopy and abdominopelvic computed tomography were performed to evaluate the recurrence. The median follow-up for all patients was 44.5 months (range, 0-271 months). We performed 1:1 propensity score matching using three covariates (age, sex, and pathologic stage) to match 77 patients who had splenectomy and 77 patients who did not.

The clinicopathologic characteristics of age, sex, primary disease at 1st operation (benign or malignant), 1st operation reconstruction method (Billroth I, Billroth II, or others), the site of recurrence (anastomosis or remnant), remnant gastric cancer histology (differentiated or undifferentiated), remnant gastric cancer Lauren type, Bormann classification, remnant gastric cancer size, remnant gastric cancer pathologic stage (including depth of invasion, lymph node metastasis), number of dissected lymph nodes, lymphatic invasion, venous invasion, perineural invasion were reviewed in patient medical records. Tumor histology was dichotomized as differentiated, which included papillary adenocarcinoma, and well or moderately differentiated adenocarcinoma, or undifferentiated, which included poorly or undifferentiated adenocarcinoma, signet ring cell carcinoma, mucinous carcinoma and other types. The pathologic stage was classified according to the eighth edition of the American Joint Committee on Cancer classification. We obtained the survival data of included patients from their updated medical records and the National Statistical Office in South Korea. This study was approved by the Institutional Review Board of Samsung Medical Center, Seoul, Korea (IRB No. SMC 2020-07033-001). Informed consent was waived.

To control for confounders, we matched two study groups (no splenectomy vs. splenectomy, 1:1) by using the propensity scores. The matching factors were age, sex, and pathologic stage. Before matching, we used chi-square for categorical variables and Wilcoxon rank-sum test for continuous variables. We used generalized estimating equations for analyzing all variables of the matched patients. The 5-year overall survival (OS) and disease-free survival (DFS) were calculated by the Kaplan-Meier method. The variables with $\mathrm{P}<0.05$ on univariate analysis using Cox regression were included for multivariate analysis to identify independent prognostic factors. Before the multivariate analysis, we also excluded the variables with variance inflation factor $>10$ to avoid multicollinearity. $P$ values $<0.05$ were considered significant in statistical assessment. Statistical analysis was carried out using SAS version 9.4 (SAS Institute, Cary, NC, USA) and SPSS version 25.0 for Windows (IBM Corp., Armonk, NY, USA).

\section{RESULTS}

\section{Patient characteristics}

Among 285 patients, 208 patients (72.98\%) had completion total gastrectomy without splenectomy (no splenectomy group) and 77 patients (27.02\%) with splenectomy (splenectomy group). Before propensity score matching, two groups showed statistically significant differences in several parameters. Tumor size of the patients who had splenectomy was larger than those who did not underwent splenectomy $(\mathrm{P}=0.004)$. The splenectomy group showed more proportion of diffuse Lauren type than the no splenectomy group ( $49.35 \%$ vs. $42.31 \%, \mathrm{P}=0.043$ ). The proportion of subserosa (T3) or serosa (T4) invasion, N1 or more stage, pathologic stage III was significantly higher in the splenectomy group than no splenectomy group (depth of invasion [T3 and T4], 54.55\% vs. 35.58\%, $\mathrm{P}=0.0333$; N1+, $44.16 \%$ vs. $16.82 \%, \mathrm{P}<0.001$; pathologic stage III, $37.66 \%$ vs. $15.38 \%, \mathrm{P}<0.001$ ). In addition, the presence of lymphatic, venous and perineural invasion was more frequent in the splenectomy group than no splenectomy group, which was statistically significant (lymphatic invasion, $\mathrm{P}<0.001$; venous invasion, $\mathrm{P}<0.001$; perineural invasion, $\mathrm{P}=0.014$ ). After $1: 1$ propensity matching with age, sex and pathologic stage, we found that vari- 
ables which were statistically significant before matching, became similar between the two study groups (Table 1).

\section{Survival}

In unmatched patients, there were significant differences in the 5-year OS and 5-year DFS between two groups (no splenectomy vs. splenectomy: 5 -year $\mathrm{OS}, 76.92 \%$ vs. $60.24 \%, \mathrm{P}=0.007$; 5 -year DFS, $86.01 \%$ vs. $69.75 \%, \mathrm{P}=0.005$ ) (Fig. $1 \mathrm{~A}$ and $\mathrm{B}$ ). Whereas, in matched patients, survivals were not significantly different (no splenectomy vs. splenectomy: 5-year OS, $61.51 \%$ vs. $60.24 \%$, $\mathrm{P}=0.884$; 5 -year DFS, $74.88 \%$ vs. $69.75 \%, \mathrm{P}=0.880$ ) (Fig. $1 \mathrm{C}$ and D). Table 2 shows the univariate and multivariate analysis of OS and recurrence-free survival in the matched patients.

Factors which were significant in the univariate analysis in terms of OS were as follows: recurred site, tumor size, histologic type, Borrmann classification, depth of invasion, lymph node metastasis, number of metastatic lymph nodes, pathologic stage, lymphatic invasion, venous invasion, and perineural invasion (Table 2). In multivariate analysis, there was no independent prognostic factor of OS.

In univariate analysis of recurrence-free survival, the statistically significant factors were as follows: tumor size, Borrmann classification, depth of invasion, lymph node metastasis, number of metastatic lymph nodes, pathologic stage, lymphatic invasion, venous invasion, and perineural invasion (Table 2). No factor was prognostic factor of the DFS in the multivariate analysis.

\section{DISCUSSION}

In this study, 5-year OS and 5-year DFS were compared between the group with and without splenectomy during completion total gastrectomy in patients with remnant gastric cancer. In propensity matched patients, there were no significant differences both in the 5-year OS and 5-year DFS.

The effectiveness of splenectomy has remained uncertain [12]. Routine splenectomy during gastric resection is not recommended because it is known that splenectomy do not improve survival rather increases morbidity and mortality [13]. Spleen has many functions, and among that functions, the major contribution of spleen is immune response, and splenectomy could leads to negative effect for host defense [14]. Previous research reported that complications such as abdominal infection and effusion were significantly increased in patients who had splenectomy. Regardless of TNM stage, there was no difference in survival rate between patients who underwent splenectomy and those who did not [15]. There have been many studies on the effectiveness of splenectomy in gastric cancer patients. Yang et al. [16] reported that splenecto- my could not increase the OS rate in gastric cancer. And there was no significant difference on postoperative mortality and morbidity. Yu et al. [17] reported that splenectomy did not improve survival rate in proximal gastric cancer.

On the other hand, Li et al. [18] reported that the spleen preserving lymphadenectomy demonstrated better survival rate in patients with advanced middle third gastric cancer. Kosuga et al. [19] reported that lymph node dissection at the splenic hilum by splenectomy might improve a survival in patients with primary gastric cancer localized on the greater curvature and Borrmann type IV.

Role of splenectomy for remnant gastric cancer is controvertible issue. Komatsu et al. [20] reported that the lymphatic flow in the remnant stomach has changed since the initial distal gastrectomy. For this reason, the need for lymphadenectomy including jejunal mesentery and splenic hilar lymph node was suggested for treatment of remnant gastric cancer. In previous studies, high rate of splenic hilar metastasis was reported in remnant gastric cancer [11]. However, few studies have been conducted to evaluate the benefits of splenectomy in remnant gastric cancer. Sugita et al. [6] performed the retrospective study on the significance of lymphadenectomy with splenectomy in the surgical treatment of advanced remnant gastric cancer. Patients with pT3/pT4 remnant gastric cancer who underwent lymphadenectomy with splenectomy reported better survival rates compared with patients who did not. However, this was not observed in the patients with pT1/pT2 remnant gastric cancer. However, Sugita's study did not stratify stages. They only classified the patient's stages into two groups. This might be the reason why splenectomy was meaningful in the advanced stage in their research.

Son et al. [21] reported that in patients with remnant gastric cancer, prophylactic splenectomy did not affect OS, regardless of stage. Also, they found that metastasis to the mesojejunal lymph node was relatively high (31.8\%), but metastasis to the splenic hilum $(6.3 \%)$ and distal splenic artery $(12.5 \%)$ was not.

In our study, we found that splenectomy was not affected survival after propensity score matching which is control the confounding factors. Although splenectomy is required for complete lymph node dissection in remnant gastric cancer, lymph node metastasis to splenic hilum may not frequently occur. Depending on the initial surgical technique of distal gastrectomy, lymphatic flow may have changed differently. Indeed, in Son's study, metastasis toward splenic hilum was observed only in the group with Billroth II/ Roux-en-Y gastrojejunostomy. Similar results were reported in our study, where metastasis of lymph node 10 (splenic hilum) was found in only one case in 2019.

The limitation of this study is that it is a retrospective study. So, there may be an information bias. After matching, our study in- 
Table 1. Clinicopathological characteristics of patients whom underwent completion total gastrectomy due to remnant gastric cancer, before and after propensity score matching

\begin{tabular}{|c|c|c|c|c|c|c|}
\hline \multirow[b]{2}{*}{ Characteristics } & \multicolumn{3}{|c|}{ Before matching } & \multicolumn{3}{|c|}{ After matching } \\
\hline & $\begin{array}{l}\text { No splenectomy } \\
\quad(n=208)\end{array}$ & $\begin{array}{c}\text { Splenectomy } \\
(n=77)\end{array}$ & P-value ${ }^{b)}$ & $\begin{array}{l}\text { No splenectomy } \\
\quad(n=77)\end{array}$ & $\begin{array}{c}\text { Splenectomy } \\
(n=77)\end{array}$ & P-value ${ }^{c)}$ \\
\hline Age (yr) & $63.5(53.0-69.5)$ & $63.0(53.0-69.0)$ & 0.596 & $63.0(55.0-69.0)$ & $63.0(53.0-69.0)$ & 0.675 \\
\hline Sex & & & 0.680 & & & 0.403 \\
\hline Male & 160 (76.92) & 61 (79.22) & & 65 (84.42) & 61 (79.22) & \\
\hline Female & 48 (23.08) & 16 (20.78) & & 12 (15.58) & 16 (20.78) & \\
\hline 1st diagnosis & & & 0.821 & & & 0.462 \\
\hline Benign & $46(22.12)$ & 18 (23.38) & & $22(28.57)$ & 18 (23.38) & \\
\hline Malignancy & 162 (77.88) & 59 (76.62) & & 55 (71.43) & 59 (76.62) & \\
\hline 1st reconstruction & & & 0.427 & & & 0.628 \\
\hline Billroth I & 88 (42.31) & 27 (35.06) & & $32(41.56)$ & 27 (35.06) & \\
\hline Billroth II & 112 (53.85) & 48 (62.34) & & $44(57.14)$ & 48 (62.34) & \\
\hline Others & $8(3.85)$ & $2(2.60)$ & & $1(1.30)$ & $2(2.60)$ & \\
\hline Recurred site & & & 0.893 & & & 0.871 \\
\hline Anastomosis & $91(43.75)$ & $33(42.86)$ & & $34(44.16)$ & $33(42.86)$ & \\
\hline Remnant & $117(56.25)$ & $44(57.14)$ & & 43 (55.84) & $44(57.14)$ & \\
\hline Tumor size $(\mathrm{cm})$ & $3.0(2.0-5.0)$ & $4.0(2.7-6.0)$ & $0.004^{d)}$ & $3.7(3.6-6.0)$ & $4.0(2.7-6.0)$ & 0.660 \\
\hline Lauren type & & & 0.043 & & & 0.232 \\
\hline Intestinal & $91(43.75)$ & $23(29.87)$ & & 33 (42.86) & $23(29.87)$ & \\
\hline Diffuse & $88(42.31)$ & $38(49.35)$ & & $32(41.56)$ & 38 (49.35) & \\
\hline Mixed & 20 (9.62) & $7(9.09)$ & & 8 (10.39) & $7(9.09)$ & \\
\hline Others/unknown & $9(4.33)$ & 9 (11.69) & & $4(5.19)$ & 9 (11.69) & \\
\hline Histologic type & & & 0.262 & & & 0.392 \\
\hline Differentiated & 77 (37.02) & $23(29.87)$ & & 28 (36.36) & $23(29.87)$ & \\
\hline Undifferentiated & 131 (62.98) & 54 (70.13) & & $49(63.64)$ & 54 (70.13) & \\
\hline Borrmann & & & 0.067 & & & 0.746 \\
\hline EGC & 110 (52.88) & 27 (35.06) & & $32(41.56)$ & 27 (35.06) & \\
\hline Type 1,2,3 and unclassifiable & $91(43.74)$ & $43(55.85)$ & & $42(54.55)$ & $43(55.85)$ & \\
\hline Type 4 & $7(3.37)$ & $7(9.09)$ & & $3(3.90)$ & $7(9.09)$ & \\
\hline Depth of invasion & & & 0.033 & & & 0.484 \\
\hline $\mathrm{T} 1, \mathrm{~T} 2$ & $134(64.42)$ & $35(45.45)$ & & $34(44.15)$ & $35(45.45)$ & \\
\hline $\mathrm{T} 3, \mathrm{~T} 4$ & $74(35.58)$ & $42(54.55)$ & & $43(55.84)$ & $42(54.55)$ & \\
\hline LN metastasis & & & $<0.001$ & & & 0.057 \\
\hline NO & $173(83.17)$ & $43(55.84)$ & & $54(70.13)$ & $43(55.84)$ & \\
\hline $\mathrm{N} 1, \mathrm{~N} 2, \mathrm{~N} 3$ & $35(16.82)$ & $34(44.16)$ & & $23(29.87)$ & $34(44.16)$ & \\
\hline Dissected LNs & $9.0(3.5-18.5)$ & $12.0(6.0-23.0)$ & $0.046^{d)}$ & $10.0(4.0-23.0)$ & $12.0(6.0-23.0)$ & 0.402 \\
\hline Metastatic LNs & $0(0-0)$ & $0(0-2)$ & $<0.001$ & $0(0-2)$ & $0(0-2)$ & 0.150 \\
\hline Dissected \# 10 LN & & & $<0.001$ & & & $<0.001$ \\
\hline No & $92(44.23)$ & 0 & & $26(33.77)$ & 0 & \\
\hline Yes & $116(55.77)$ & $77(100)$ & & $51(66.23)$ & $77(100)$ & \\
\hline Pathologic stage $e^{\text {a) }}$ & & & $<0.001$ & & & 1.000 \\
\hline I, II & 176 (84.62) & $48(62.34)$ & & $48(62.34)$ & $48(62.34)$ & \\
\hline III & $32(15.38)$ & $29(37.66)$ & & $29(37.66)$ & $29(37.66)$ & \\
\hline Lymphatic invasion & & & $<0.001$ & & & 0.007 \\
\hline No & $125(60.10)$ & 25 (32.47) & & 41 (53.25) & 25 (32.47) & \\
\hline Yes & 64 (30.77) & $36(46.75)$ & & $31(40.26)$ & $36(46.75)$ & \\
\hline Unknown & 19 (9.13) & 16 (20.78) & & $5(6.49)$ & 16 (20.78) & \\
\hline
\end{tabular}

(Continued to the next page) 
Table 1. Continued

\begin{tabular}{|c|c|c|c|c|c|c|}
\hline \multirow[b]{2}{*}{ Characteristics } & \multicolumn{3}{|c|}{ Before matching } & \multicolumn{3}{|c|}{ After matching } \\
\hline & $\begin{array}{l}\text { No splenectomy } \\
\quad(n=208)\end{array}$ & $\begin{array}{l}\text { Splenectomy } \\
\quad(n=77)\end{array}$ & P-value $e^{\text {b) }}$ & $\begin{array}{l}\text { No splenectomy } \\
\qquad(n=77)\end{array}$ & $\begin{array}{l}\text { Splenectomy } \\
\quad(n=77)\end{array}$ & P-value \\
\hline Venous invasion & & & $<0.001$ & & & 0.004 \\
\hline No & $170(81.73)$ & $45(58.44)$ & & $63(81.82)$ & $45(58.44)$ & \\
\hline Yes & $16(7.69)$ & $13(16.88)$ & & 8 (10.39) & $13(16.88)$ & \\
\hline Unknown & $22(10.58)$ & $19(24.68)$ & & $6(7.79)$ & $19(24.68)$ & \\
\hline Perineural invasion & & & 0.014 & & & 0.065 \\
\hline No & $128(61.54)$ & $33(42.86)$ & & $43(55.84)$ & $33(42.86)$ & \\
\hline Yes & $54(25.96)$ & $27(35.06)$ & & $27(35.06)$ & $27(35.06)$ & \\
\hline Unknown & $26(12.50)$ & $17(22.08)$ & & 7 (9.09) & 17 (22.08) & \\
\hline
\end{tabular}

Values are presented as median (interquartile range) or number (\%). Matching factors were age, sex and pathologic stage.

${ }^{a)}$ According to the 8th edition of the American Joint Committee on Cancer classification. Statistical analysis with ${ }^{b)}$ chi-square test or ${ }^{\mathrm{c}}$ Wilcoxon rank-sum test, and ${ }^{d)}$ generalized estimating equation.

EGC, early gastric cancer; LN, lymph node.

Overall survival of unmatched patients

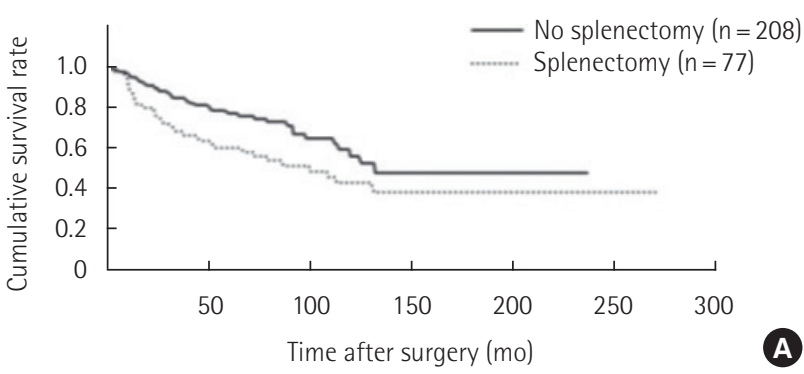

Overall survival of matched patients



Recurrence-free survival of unmatched patients

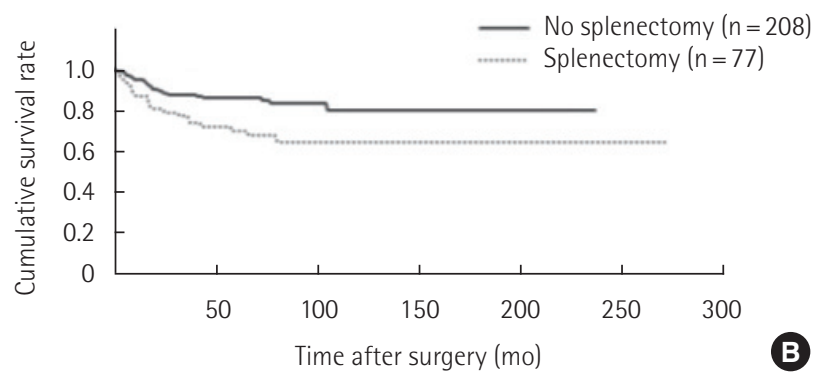

Recurrence-free survival of matched patients

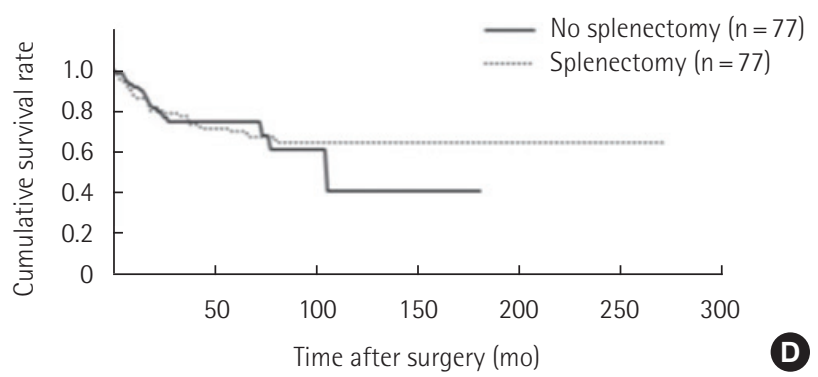

Fig. 1. OS and recurrence-free survival in the unmatched/matched patients who underwent completion total gastrectomy due to remnant gastric cancer. The OS (A) and recurrence-free survival (B) of the unmatched patients who had splenectomy were significantly lower than those who did not underwent splenectomy (no splenectomy vs. splenectomy: 5-year OS, 76.92\% vs. 60.24\%, $P=0.007 ; 5-y e a r$ DFS, 86.01\% vs. $69.75 \%, P=0.005)$. When we analyzed the matched patients, there were no significant differences in OS (C) and recurrence-free survival (D) between those who had splenectomy and those who preserved the spleen (no splenectomy vs. splenectomy: 5-year 0S, 61.51\% vs. $60.24 \%, \mathrm{P}=0.884 ;$-year $\mathrm{DFS}, 74.88 \%$ vs. $69.75 \%, \mathrm{P}=0.880$ ). OS, overall survival; $\mathrm{DFS}$, disease-free survival.

cluded only 77 patients in each group. As we reviewed the medical records of 390 patients between September 1996 and December 2017, we could not consider the development of medical technology such as surgical technique and adjuvant chemotherapy and these would certainly have affected the patient's prognosis.

In conclusion, splenectomy has no effect on the OS and DFS in patients with remnant gastric cancer. Therefore, splenectomy during completion total gastrectomy may not be necessary. 


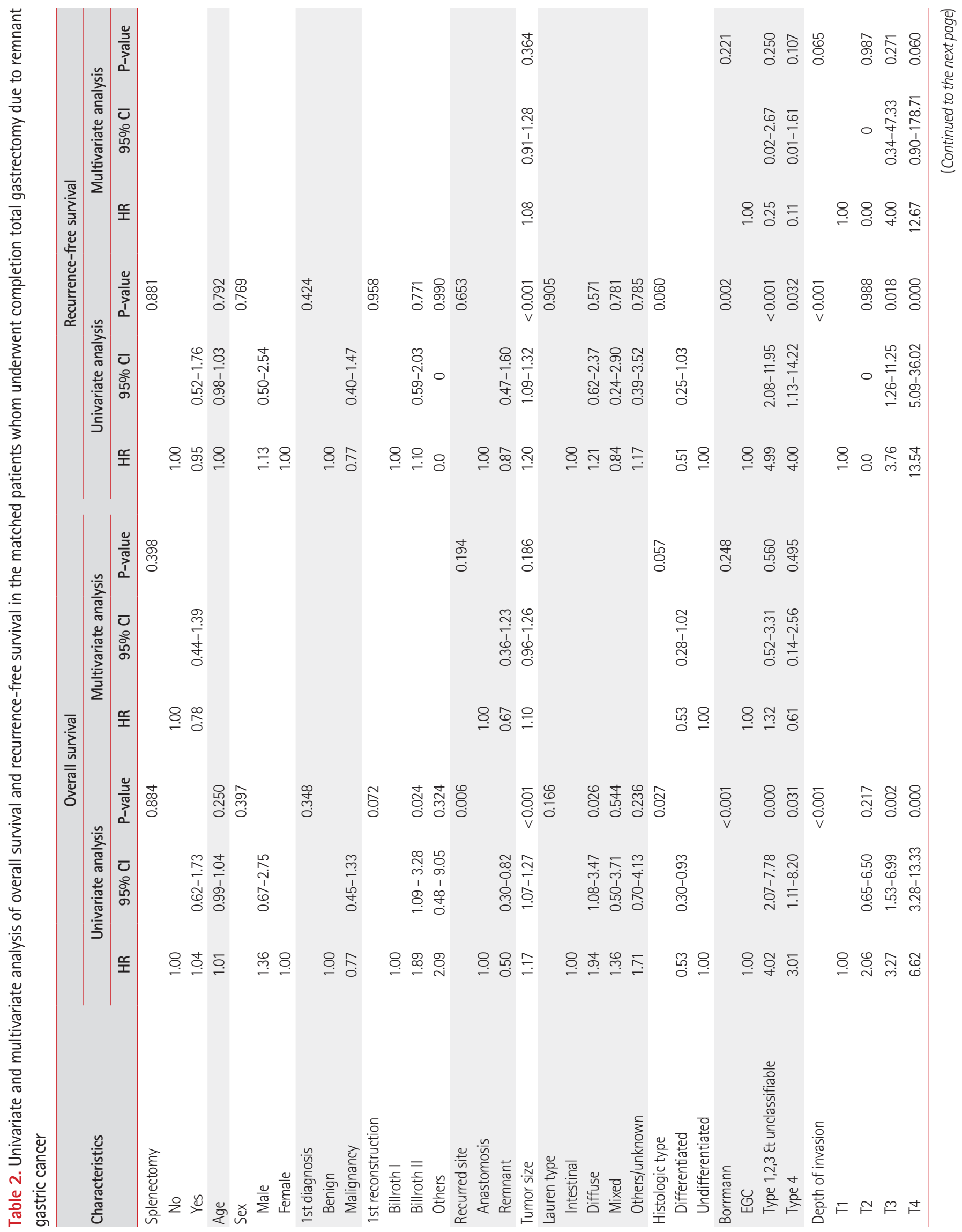




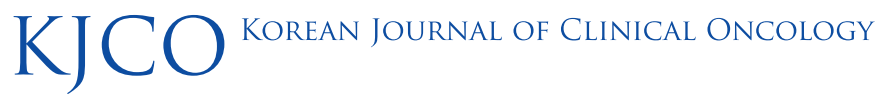

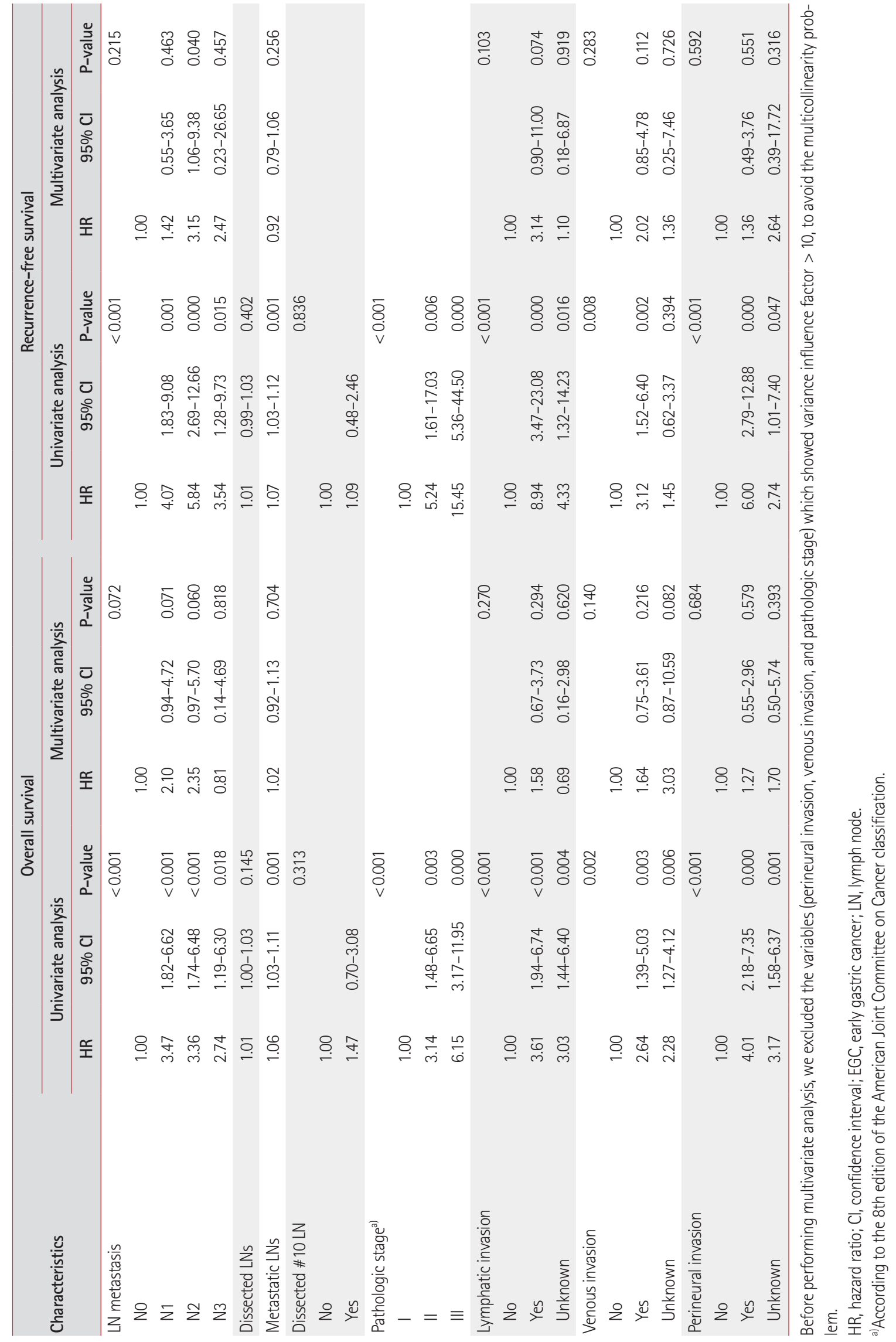




\section{CONFLICT OF INTEREST}

No potential conflict of interest relevant to this article was reported.

\section{ACKNOWLEDGMENTS}

The authors wound like to thank the Statistics and Data Center in Samsung Medical Center for help with the data analysis and statistics.

JHL contributed to the conception of this study and provided critical revision of the study. SEO and SHB collected and analyzed the data and drafted the work. JYA, MGC, TSS, and JMB ensured that questions related to the accuracy or integrity of all parts of the work were appropriately investigated and resolved. All authors gave final approval of the version to be published.

\section{REFERENCES}

1. Ohira M, Toyokawa T, Sakurai K, Kubo N, Tanaka H, Muguruma $\mathrm{K}$, et al. Current status in remnant gastric cancer after distal gastrectomy. World J Gastroenterol 2016;22:2424-33.

2. Mezhir JJ, Gonen M, Ammori JB, Strong VE, Brennan MF, Coit DG. Treatment and outcome of patients with gastric remnant cancer after resection for peptic ulcer disease. Ann Surg Oncol 2011; 18:670-6

3. Thorban S, Bottcher K, Etter M, Roder JD, Busch R, Siewert JR. Prognostic factors in gastric stump carcinoma. Ann Surg 2000;231: 188-94.

4. Ikeguchi M, Kondou A, Shibata S, Yamashiro H, Tsujitani S, Maeta $\mathrm{M}$, et al. Clinicopathologic differences between carcinoma in the gastric remnant stump after distal partial gastrectomy for benign gastroduodenal lesions and primary carcinoma in the upper third of the stomach. Cancer 1994;73:15-21.

5. Ohashi M, Katai H, Fukagawa T, Gotoda T, Sano T, Sasako M. Cancer of the gastric stump following distal gastrectomy for cancer. Br J Surg 2007;94:92-5.

6. Sugita H, Oda E, Hirota M, Ishikawa S, Tomiyasu S, Tanaka H, et al. Significance of lymphadenectomy with splenectomy in radical surgery for advanced (pT3/pT4) remnant gastric cancer. Surgery 2016;159:1082-9.

7. Ahn HS, Kim JW, Yoo MW, Park DJ, Lee HJ, Lee KU, et al. Clinicopathological features and surgical outcomes of patients with remnant gastric cancer after a distal gastrectomy. Ann Surg Oncol 2008;15:1632-9.

8. Kwon IG, Cho I, Choi YY, Hyung WJ, Kim CB, Noh SH. Risk fac- tors for complications during surgical treatment of remnant gastric cancer. Gastric Cancer 2015;18:390-6.

9. Shin SH, Jung H, Choi SH, An JY, Choi MG, Noh JH, et al. Clinical significance of splenic hilar lymph node metastasis in proximal gastric cancer. Ann Surg Oncol 2009;16:1304-9.

10. Kunisaki C, Shimada H, Nomura M, Hosaka N, Akiyama H, Ookubo K, et al. Lymph node dissection in surgical treatment for remnant stomach cancer. Hepatogastroenterology 2002;49:580-4.

11. Sinning C, Schaefer N, Standop J, Hirner A, Wolff M. Gastric stump carcinoma: epidemiology and current concepts in pathogenesis and treatment. Eur J Surg Oncol 2007;33:133-9.

12. Aoyagi K, Kouhuji K, Miyagi M, Imaizumi T, Kizaki J, Shirouzu K. Prognosis of metastatic splenic hilum lymph node in patients with gastric cancer after total gastrectomy and splenectomy. World J Hepatol 2010;2:81-6.

13. Noguchi Y, Yoshikawa T, Tsuburaya A, Motohashi H, Karpeh MS, Brennan MF. Is gastric carcinoma different between Japan and the United States? Cancer 2000;89:2237-46.

14. Cadili A, de Gara C. Complications of splenectomy. Am J Med 2008;121:371-5.

15. Yao XX, Sah BK, Yan M, Chen MM, Zhu ZG. Radical gastrectomy with combined splenectomy: unnecessary. Hepatogastroenterology 2011;58:1067-70.

16. Yang K, Chen XZ, Hu JK, Zhang B, Chen ZX, Chen JP. Effectiveness and safety of splenectomy for gastric carcinoma: a meta-analysis. World J Gastroenterol 2009;15:5352-9.

17. Yu W, Choi GS, Chung HY. Randomized clinical trial of splenectomy versus splenic preservation in patients with proximal gastric cancer. Br J Surg 2006;93:559-63.

18. Li C, Kim S, Lai JF, Oh SJ, Hyung WJ, Choi WH, et al. Lymph node dissection around the splenic artery and hilum in advanced middle third gastric carcinoma. Eur J Surg Oncol 2009;35:709-14.

19. Kosuga T, Ichikawa D, Okamoto K, Komatsu S, Shiozaki A, Fujiwara $\mathrm{H}$, et al. Survival benefits from splenic hilar lymph node dissection by splenectomy in gastric cancer patients: relative comparison of the benefits in subgroups of patients. Gastric Cancer 2011; 14:172-7.

20. Komatsu S, Ichikawa D, Okamoto K, Ikoma D, Tsujiura M, Shiozaki A, et al. Differences of the lymphatic distribution and surgical outcomes between remnant gastric cancers and primary proximal gastric cancers. J Gastrointest Surg 2012;16:503-8.

21. Son SY, Kong SH, Ahn HS, Park YS, Ahn SH, Suh YS, et al. The value of $\mathrm{N}$ staging with the positive lymph node ratio, and splenectomy, for remnant gastric cancer: a multicenter retrospective study. J Surg Oncol 2017;116:884-93. 